\title{
Structure-Based Discovery of Novel Amide-Containing Nicotinamide Phosphoribosyltransferase (Nampt) Inhibitors
}

Xiaozhang Zheng ${ }^{\mathrm{a} *}$, Paul Bauer ${ }^{\mathrm{a}}$, Timm Baumeister ${ }^{\mathrm{a}}$, Alexandre J. Buckmelter ${ }^{\mathrm{a}}$, Maureen Caligiuri $^{\mathrm{a}}$, Karl H. Clodfelter ${ }^{\mathrm{a}}$, Bingsong Han ${ }^{\mathrm{a}}$, Yen-Ching Ho ${ }^{\mathrm{a}}$, Nikolai Kley ${ }^{\mathrm{a}}$, Jian Lin ${ }^{\mathrm{a}}$, Dominic J. Reynolds ${ }^{\mathrm{a}}$, Geeta Sharma ${ }^{\mathrm{a}}$, Chase C. Smith ${ }^{\mathrm{a}}$, Zhongguo Wang ${ }^{\mathrm{a}}$, Peter S. Dragovich ${ }^{\mathrm{b}}$, Janet Gunzner-Toste ${ }^{\mathrm{b}}$, Bianca M. Liederer ${ }^{\mathrm{b}}$, Justin Ly ${ }^{\mathrm{b}}$, Thomas O’Brien ${ }^{\mathrm{b}}$, Angela $\mathrm{Oh}^{\mathrm{b}}$, Leslie Wang $^{\mathrm{b}}$, Weiru Wang ${ }^{\mathrm{b}}$, Yang Xiao ${ }^{\mathrm{b}}$, Mark Zak ${ }^{\mathrm{b}}$, Guiling Zhao ${ }^{\mathrm{b}}$, Po-wai Yuen ${ }^{\mathrm{c}}$, Kenneth W. Bair ${ }^{\mathrm{a}}$

${ }^{a}$ Forma Therapeutics, Inc., 500 Arsenal Street, Watertown, Massachusetts 02472, USA

${ }^{\mathrm{b}}$ Genentech, Inc., 1 DNA Way, South San Francisco, California 94080, USA

${ }^{\mathrm{c}}$ Pharmaron Beijing, Co. Ltd., 6 Tai He Road, BDA Beijing, 100176, P. R. China

Table of contents:

Title page

Expression, purification, and crystallization of human Nampt

LCMS Methods

Phosphoribosylated adducts detection

In vitro ADME assays

In vitro Methods for the Determination of Nampt Inhibition and Cell Proliferation 


\section{Expression, purification, and crystallization of human Nampt}

The expression construct of NAMPT for structural studies was obtained from professor Yigong Shi's group (Tsinghua University, Beijing, China).

The C-terminal His-tagged NAMPT M1-H491 construct was transformed into BL21 codon optimized cells. Cells were grown at $37{ }^{\circ} \mathrm{C}$ to an absorbance of $0.5\left(\mathrm{OD}_{600}\right)$ in LB media containing $50 \mu \mathrm{g} / \mathrm{mL}$ of carbenicillin and then transferred to $22{ }^{\circ} \mathrm{C}$ prior to induction with $1 \mathrm{mM}$ IPTG at an absorbance of $0.8\left(\mathrm{OD}_{600}\right)$. Cells were harvested 16 hours post induction and the pellet was lysed by passing through a microfluidizer in a buffer containing $20 \mathrm{mM}$ TrisCl, $\mathrm{pH}$ 8.0, $200 \mathrm{mM} \mathrm{NaCl}, 5 \mathrm{mM}$ imidazole, $1 \mathrm{mM}$ TCEP and EDTA-free protease inhibitor tablets (Roche). Cell lysates were loaded onto a HisTrap HP column (GE Healthcare) in a buffer containing $20 \mathrm{mM}$ TrisCl, $\mathrm{pH} 8.0,500 \mathrm{mM} \mathrm{NaCl}, 5 \mathrm{mM}$ imidazole and $1 \mathrm{mM}$ TCEP and the bound Nampt was eluted with $250 \mathrm{mM}$ imidazole in the same buffer. The protein was then loaded onto a $5 \mathrm{~mL}$ Q HP column (GE Healthcare) in a buffer containing $25 \mathrm{mM}$ TrisCl, $\mathrm{pH} 8.0$ and $1 \mathrm{mM}$ TCEP and eluted at $300 \mathrm{mM} \mathrm{NaCl}$ with a linear gradient of the same buffer and $1.0 \mathrm{M}$ $\mathrm{NaCl}$. The protein was further purified on a size-exclusion Superdex 75 column (GE Healthcare) in a buffer containing $25 \mathrm{mM}$ TrisCl, $\mathrm{pH} 8.0,150 \mathrm{mM} \mathrm{NaCl}$ and $5 \mathrm{mM}$ DTT. Fractions containing Nampt were pooled and concentrated to $6 \mathrm{mg} / \mathrm{mL}$ and confirmed by SDS-PAGE showing that the purity was greater than $95 \%$.

Diffraction quality crystals were grown at $19{ }^{\circ} \mathrm{C}$ from $0.2 \mu \mathrm{L}+0.2 \mu \mathrm{L}$ vapor diffusion drops containing $6 \mathrm{mg} / \mathrm{mL}$ Nampt, $0.1 \mathrm{M}$ sodium phosphate, $\mathrm{pH}$ 8.6-9.0, 25-29\% polyethylene glycol 3350, $0.2 \mathrm{M} \mathrm{NaCl}$ and $1 \mathrm{mM}$ compound, which were then streak-seeded using Hampton's 
seeding tool. Plate crystals appeared overnight and harvested for data collection with 15\% ethylene glycol in the crystallization solution.

The diffraction data set of compound 7 was collected at ALS beamline 502 and processed with the HKL2000 package. The diffraction data set of compound $\mathbf{5 8}$ was collected at Shanghai Synchrotron Radiation Facility (SSRF) beam line BL17U1 and also processed with the HKL2000 package. Further processing was carried out with programs from the CCP4 suite. Data collection and structure refinement statistics are summarized in Table S1.

The structure was solved by molecular replacement (MR) with known Nampt structure (PDB code:3DHF) as the search model using the program Phaser. The structure was further refined using program REFMAC5 (Murshudov, G. N.; et al., Acta Crystallogr. D Biol. Crystallogr. 1997, 53, 240-255) and PHENIX (Adams, P. D.; et al., Acta Crystallogr. D Biol. Crystallogr. 2010, 66, 213-221) using the maximum likelihood target functions, anisotropic individual Bfactor refinement method, and TLS refinement method, to achieve convergence. The data and refinement statistics are shown in Table S1. PDB nos.: 4KFN for 7 complexed with Nampt; 4KFO for $\mathbf{5 8}$ complexed with Nampt.

Table S1 X-ray crystallography data and refinement statistics

\begin{tabular}{|c|c|c|}
\hline \multicolumn{3}{|c|}{ Data collection } \\
\hline & 58 & 7 \\
\hline Space group & $\mathrm{P} 2_{1}$ & $\mathrm{P} 2_{1}$ \\
\hline Unit cell & $\mathrm{a}=60.8 \AA$ & $a=60.5 \AA$, \\
\hline
\end{tabular}




\begin{tabular}{|c|c|c|}
\hline & $\begin{array}{l}b=106.4 \AA, c=82.9 \AA, \\
\alpha=90^{\circ} \beta=96.6^{\circ} \gamma=90^{\circ}\end{array}$ & $\begin{array}{l}b=106.6 \AA ̊ A=83.0 \AA, \\
\alpha=90^{\circ} \beta=96.7^{\circ} \gamma=90^{\circ}\end{array}$ \\
\hline Resolution & $1.60 \AA$ & $1.60 \AA$ \\
\hline Total number of reflections & $127910(9917)^{1}$ & $135066(13199)^{1}$ \\
\hline Completeness & $0.932(0.727)$ & $0.977(0.961)$ \\
\hline Redundancy & $2.6(1.8)$ & $3.8(3.7)$ \\
\hline $1 / \sigma$ & $13.5(2.3)$ & $14.8(2.2)$ \\
\hline Rsym $^{2}$ & $0.067(0.334)$ & $0.075(0.613)$ \\
\hline \multicolumn{3}{|l|}{ Refinement } \\
\hline Resolution range & $50-1.60 \AA ̊$ & $50-1.60 \AA$ \\
\hline Rcryst $^{3} /$ Rfree $^{4}$ & $0.156 / 0.181$ & $0.156 / 0.183$ \\
\hline Non-hydrogen atoms & 8712 & 8874 \\
\hline Water molecules & 1038 & 1165 \\
\hline Average B, Overall & 19.74 & 14.11 \\
\hline Protein & 17.90 & 11.89 \\
\hline Ligand & 22.00 & 21.00 \\
\hline Water & 32.80 & 27.73 \\
\hline
\end{tabular}




\begin{tabular}{|l|l|l|}
\hline r.m.s.d. bond lengths & $0.006 \AA$ & $0.008 \AA$ \\
\hline r.m.s.d. angles & $1.061^{\circ}$ & $1.184^{\circ}$ \\
\hline Ramachandran (C/A/G/D) & $0.914 / 0.086 / 0 / 0$ & $0.980 / 0.019 / 0.001 / 0$ \\
\hline
\end{tabular}

${ }^{1}$ Values in parentheses are of the highest resolution shell, which is $1.60-1.66 \AA$.

${ }^{2}$ Rsym $=\Sigma\left|I_{h i}-I_{h}\right| / \Sigma I_{h i}$, where $I_{h i}$ is the scaled intensity of the ith symmetry-related observation of reflection $h$ and $I_{h}$ is the mean value.

${ }^{3}$ Rcryst $=\Sigma_{h}\left|F_{o h}-F_{c h}\right| / \Sigma_{h} F_{o h}$, where $F_{o h}$ and $F_{c h}$ are the observed and calculated structure factor amplitudes for reflection $h$.

${ }^{4}$ Value of Rfree is calculated for $5 \%$ randomly chosen reflections not included in the refinement. 


\section{LCMS Methods:}

\section{LCMS1:}

Instrument Information: HPLC-Agilent 1200

Column: Agilent Zorbax SB-C $18,3.5 \mu \mathrm{m}, 2.1 \mathrm{~mm}$ x $30 \mathrm{~mm}$

Mobile Phase A: Water $/ 0.1 \%$ Formic Acid

Mobile Phase B: Acetonitrile/0.1\% Formic Acid

Gradient: 15 to $95 \%$ B in 2.5 minutes, hold $95 \%$ B to 3.5 minutes, $95 \%$ B to $15 \%$ in 0.2 minutes, $15 \%$ B for 0.2 minutes, then stop.

Flow Rate: $2.0 \mathrm{~mL} / \mathrm{min}$

Column Temperature: Ambient

Detector: $220 \mathrm{~nm}$ and $254 \mathrm{~nm}$

MS Parameters: Agilent G1956B, MSD

Interface: ESI (Positive)

\section{LCMS2:}

Instrument Information: Waters Acquity UPLC

Column: Acquity UPLC BEH C $181.7 \mu \mathrm{m}, 2.1 \mathrm{~mm}$ x $50 \mathrm{~mm}$ 
Mobile Phase A: 95/5/0.1\%: 10 mM Ammonium Formate/Acetonitrile/Formic Acid

Mobile Phase B: 95/5/0.09\%: Acetonitrile/Water/Formic Acid

Gradient: 5 to $100 \%$ B in 2.0 minutes, hold $100 \%$ B to 2.2 minutes, $100 \%$ B to $5 \%$ in 0.1 minutes, $5 \%$ B for 0.2 minutes, then stop.

Flow Rate: $0.6 \mathrm{~mL} / \mathrm{min}$

Column Temperature: Ambient

Detector: $220 \mathrm{~nm}$ and $254 \mathrm{~nm}$

MS Parameters: Waters ZQ Mass Spectrometer

Interface: ESI (Positive)

\section{LCMS3:}

Instrument Information: HPLC: Waters HT2790 Alliance

Column: XBridge C18, $5 \mu \mathrm{m}, 4.6 \mathrm{~mm} \times 150 \mathrm{~mm}$

Mobile Phase A: 95\% Water $/ 5 \%$ Methanol with $0.1 \%$ Formic Acid

Mobile Phase B: 95\% Methanol/5\% Water with 0.1\% Formic Acid

Gradient: Linear 5-95\% B in 5.5 minutes, hold 95\% B to 7.5 minutes

Flow Rate: $1.2 \mathrm{~mL} / \mathrm{min}$ 
Column Temperature: Ambient

Detector: $220 \mathrm{~nm}$ and $254 \mathrm{~nm}$

MS Parameters: Waters ZQ Single Quad Mass Spectrometer

Interface: ESI (Positive)

\section{LCMS4:}

Instrument Information: SHIMADZU LCMS-2020

Column: Shim-pack XR-ODS $2.2 \mu \mathrm{m}, 50 \mathrm{~mm}$ x $3.0 \mathrm{~mm}$

Mobile Phase A: Water $/ 0.05 \%$ TFA

Mobile Phase B: Acetonitrile /0.05\% TFA

Gradient: $5 \%$ B to $100 \%$ B for 2.0 minutes, $100 \%$ B for 1.2 minutes, $100 \%$ B to $5 \%$ in 0.1 minute, then stop.

Flow Rate: $1.0 \mathrm{~mL} / \mathrm{min}$

Column Temperature: $40^{\circ} \mathrm{C}$

Detector: $254 \mathrm{~nm}$ and ELSD

Interface: ESI (Positive)

\section{LCMS5:}


Instrument Information: SHIMADZU LCMS-2010EV

Column: Waters XBridge C18 3.5 $\mu \mathrm{m}, 3.0$ x $50 \mathrm{~mm}$

Mobile Phase A: Water /5 mM Ammonium Acetate

Mobile Phase B: Methanol

Gradient: $10 \%$ to $100 \%$ B in 1.8 minutes, $100 \%$ B for 1.3 minutes, $100 \%$ to $10 \%$ B in 0.1 minutes, then stop.

Flow Rate: $0.9 \mathrm{~mL} / \mathrm{min}$

Column Temperature: $40^{\circ} \mathrm{C}$

Detector: PDA and ELSD

Interface: ESI (Positive \& Negative)

\section{LCMS6:}

Instrument Information: SHIMADZU LCMS-2020

Column: Shim-pack XR-ODS $2.2 \mu \mathrm{m}, 3.0 \mathrm{~mm}$ x $50 \mathrm{~mm}$

Mobile Phase A: Water $/ 0.05 \%$ TFA

Mobile Phase B: Acetonitrile

Gradient: $5 \%$ B to $100 \%$ B for 2.0 minutes, $100 \%$ B for 1.2 minutes, $100 \%$ B to $5 \%$ B in 0.1 minutes, then stop.

Flow Rate: $1.0 \mathrm{~mL} / \mathrm{min}$ 
Column Temperature: $40^{\circ} \mathrm{C}$

Detector: UV and ELSD

Interface: ESI (Positive)

\section{LCMS7:}

Instrument Information: SHIMADZU LCMS-2020

Column: Shim-pack XR-ODS $2.2 \mu \mathrm{m}, 3.0 \mathrm{~mm}$ x $50 \mathrm{~mm}$

Mobile Phase A: Water $/ 0.05 \%$ TFA

Mobile Phase B: Acetonitrile

Gradient: $5 \%$ to $100 \% \mathrm{~B}$ in 2.0 minutes, $100 \% \mathrm{~B}$ for 1.2 minutes, $100 \%$ to $5 \% \mathrm{~B}$ in 0.2 minutes, then stop.

Flow Rate: $1.0 \mathrm{~mL} / \mathrm{min}$

Column Temperature: $40^{\circ} \mathrm{C}$

Detector: $254 \mathrm{~nm}$ and ELSD

Interface: ESI (Positive)

\section{LCMS8:}


Instrument Information: SHIMADZU LCMS-2020EV

Column: Shim-pack XR-ODS $2.2 \mu \mathrm{m}, 50 \mathrm{~mm}$ x $3.0 \mathrm{~mm}$

Mobile Phase A: Water $/ 0.05 \%$ TFA

Mobile Phase B: Acetonitrile

Gradient: $5 \%$ to $100 \%$ B in 2.1 minutes, $100 \%$ B for 0.8 minutes, $100 \%$ to $5 \%$ B in 0.1 minutes, then stop.

Flow Rate: $1.0 \mathrm{~mL} / \mathrm{min}$

Column Temperature: $40^{\circ} \mathrm{C}$

Detector: $254 \mathrm{~nm}$ and ELSD

Interface: ESI (Positive)

\section{LCMS9:}

Instrument Information: SHIMADZU LCMS-2010EV

Column: Shim-pack XR-ODS $2.2 \mu \mathrm{m}, 3.0 \mathrm{~mm}$ x $50 \mathrm{~mm}$

Mobile Phase A: Water $/ 0.05 \%$ TFA

Mobile Phase B: Acetonitrile/0.05\% TFA

Gradient: $5 \%$ to $100 \%$ B in 2.0 minutes, $100 \%$ B for 1.1 minutes, $100 \%$ to $5 \%$ B in 0.2 minutes, then stop. 
Flow Rate: $1.0 \mathrm{~mL} / \mathrm{min}$

Column Temperature: $40{ }^{\circ} \mathrm{C}$

Detector: $254 \mathrm{~nm}$ and ELSD

Interface: ESI (Positive)

\section{LCMS10:}

Instrument Information: SHIMADZU LCMS-2020

Column: Shim-pack XR-ODS $2.2 \mu \mathrm{m}, 3.0 \mathrm{~mm}$ x $50 \mathrm{~mm}$

Mobile Phase A: Water $/ 0.05 \%$ TFA

Mobile Phase B: Acetonitrile/0.05\% TFA

Gradient: $5 \%$ to $100 \% \mathrm{~B}$ in 2.0 minutes, $100 \% \mathrm{~B}$ for 1.2 minutes, $100 \%$ to $5 \% \mathrm{~B}$ in 0.1 minutes, then stop.

Flow Rate: $1.0 \mathrm{~mL} / \mathrm{min}$

Column Temperature: $40^{\circ} \mathrm{C}$

Detector: $254 \mathrm{~nm}$ and ELSD

Interface: ESI (Positive) 


\section{LCMS11:}

Instrument Information: SHIMADZU LCMS-2020EV

Column: Shim-pack XR-ODS $2.2 \mu \mathrm{m}, 50 \mathrm{~mm}$ x $3.0 \mathrm{~mm}$

Mobile Phase A: Water $/ 0.1 \%$ TFA

Mobile Phase B: Acetonitrile $/ 0.05 \%$ TFA

Gradient: $5 \%$ to $100 \% \mathrm{~B}$ in 2.0 minutes, $100 \% \mathrm{~B}$ for 1.1 minutes, $100 \%$ to $5 \% \mathrm{~B}$ in 0.1 minutes, then stop.

Flow Rate: $1.0 \mathrm{~mL} / \mathrm{min}$

Column Temperature: $40^{\circ} \mathrm{C}$

Detector: PDA and ELSD

Interface: ESI (Positive) 


\section{Determination of phosphoribosylated adducts of compound 8, 20, 28, and 33}

Compounds were incubated with the Nampt enzyme under the standard biochemical assay conditions, and the formation of the corresponding PRPP-derived phosphoribosylated adducts was assessed by LC-MS/MS

\section{LC/MS/MS method and results for compound 8, 20, and 28}

HPLC Separation

Column - Phenomenex Hydro-RP, $4 \mu \mathrm{m}$, (50 mm x $2.0 \mathrm{~mm})$

Mobile Phase A: $\mathrm{H}_{2} \mathrm{O}, 1 \%$ Formic Acid

Mobile Phase B: Acetonitrile, 1\% Formic Acid

Gradient Programs

For compound $\mathbf{8}$ and $\mathbf{2 8}$

\begin{tabular}{|c|c|c|}
\hline $\begin{array}{c}\text { Time } \\
(\mathrm{min})\end{array}$ & $\begin{array}{c}\% \text { Mobile } \\
\text { Phase B }\end{array}$ & $\begin{array}{c}\text { Flow Rate } \\
(\mu \mathrm{L} / \mathbf{m i n})\end{array}$ \\
\hline 0.0 & 10 & 200 \\
\hline 2.0 & 10 & 200 \\
\hline 7.5 & 50 & 200 \\
\hline 8.0 & 50 & 200 \\
\hline 8.2 & 10 & 200 \\
\hline 10.0 & 10 & 200 \\
\hline
\end{tabular}

MRM Scans

Declustering Potential: $120 \mathrm{~V}$ for all inhibitor analogues

Collision Energy: Optimized condition for each compound
For compound 20

\begin{tabular}{|c|c|c|}
\hline $\begin{array}{c}\text { Time } \\
(\mathrm{min})\end{array}$ & $\begin{array}{c}\% \text { Mobile } \\
\text { Phase B }\end{array}$ & $\begin{array}{c}\text { Flow Rate } \\
(\mu \mathrm{L} / \mathbf{m i n})\end{array}$ \\
\hline 0.0 & 10 & 200 \\
\hline 2.0 & 10 & 200 \\
\hline 6.0 & 30 & 200 \\
\hline 7.5 & 80 & 200 \\
\hline 7.8 & 80 & 200 \\
\hline 8.0 & 10 & 200 \\
\hline 10.0 & 10 & 200 \\
\hline
\end{tabular}


a.

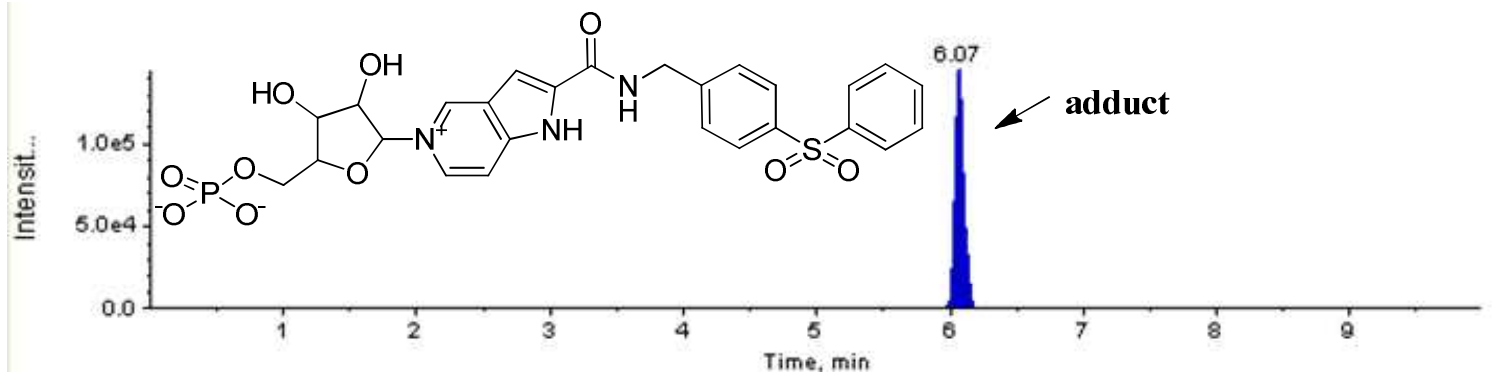

b.

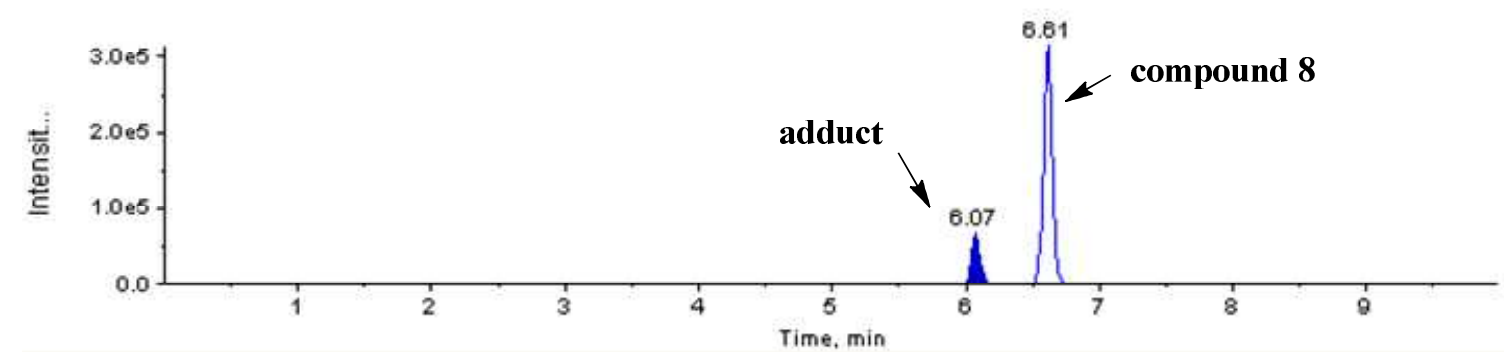

Figure 1. LC/MS/MS Chromatograms of compound 8 enzyme reaction mixture: (a) Multiple Reaction Monitoring (MRM) of transition from m/z 604.0 (adduct $\mathrm{M}+\mathrm{H}$ ion) to 392.0 (parent $\mathrm{M}+\mathrm{H}$ ion) indicating presence of phosphoribosylated adduct (b) MRM of transition from $\mathrm{m} / \mathrm{z}$ 392.0 (parent $\mathrm{M}+\mathrm{H}$ ion) to 145.3 (representing fragmentation of the left hand side of the parent) indicating presence of both parent (8) and phosphoribosylated adduct. 
a.

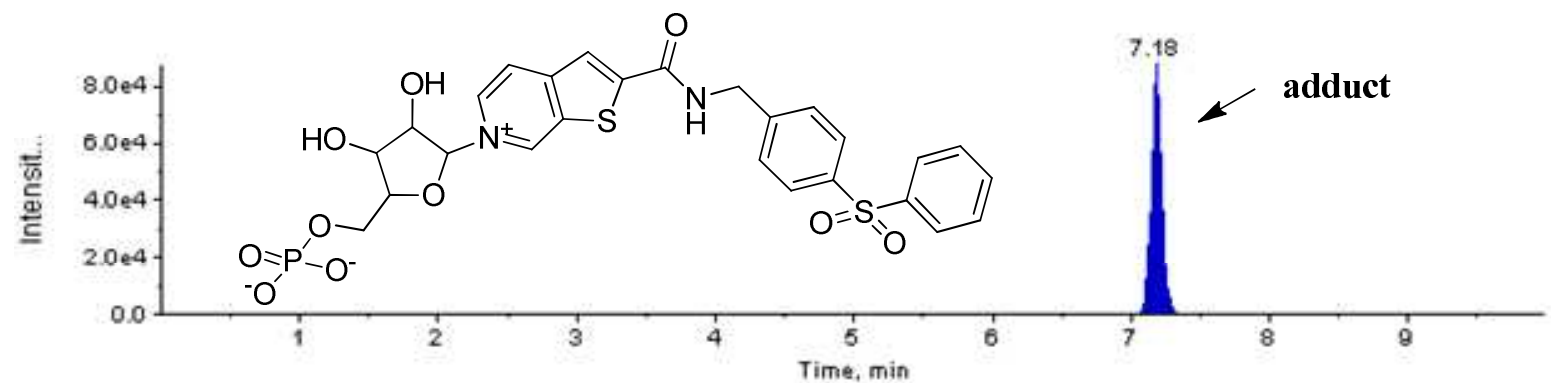

b.

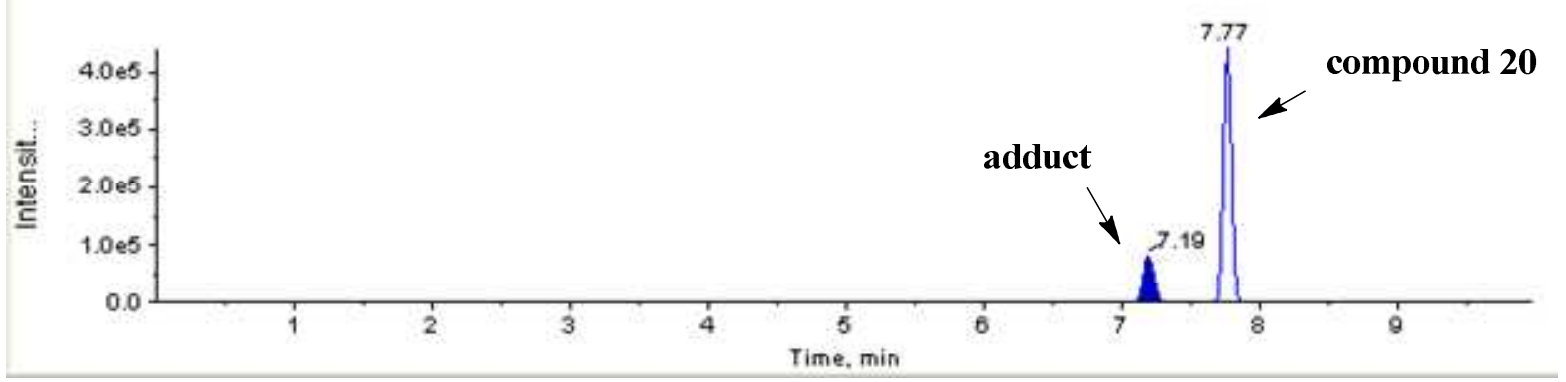

Figure 2. LC/MS/MS Chromatograms of compound 20 enzyme reaction mixture: (a) Multiple Reaction Monitoring (MRM) of transition from m/z 621.1 (adduct $\mathrm{M}+\mathrm{H}$ ion) to 409.1 (parent $\mathrm{M}+\mathrm{H}$ ion) indicating presence of phosphoribosylated adduct (b) MRM of transition from $\mathrm{m} / \mathrm{z}$ 409.1 (parent $\mathrm{M}+\mathrm{H}$ ion) to 125.2 (representing fragmentation of the left hand side of the parent) indicating presence of both parent (20) and phosphoribosylated adduct. 


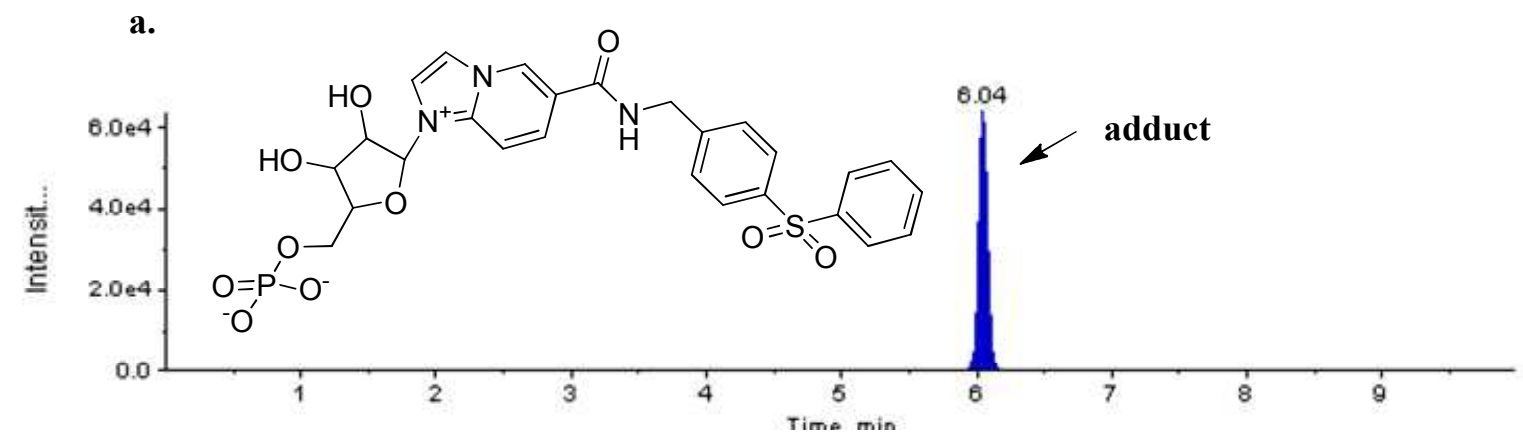

b.

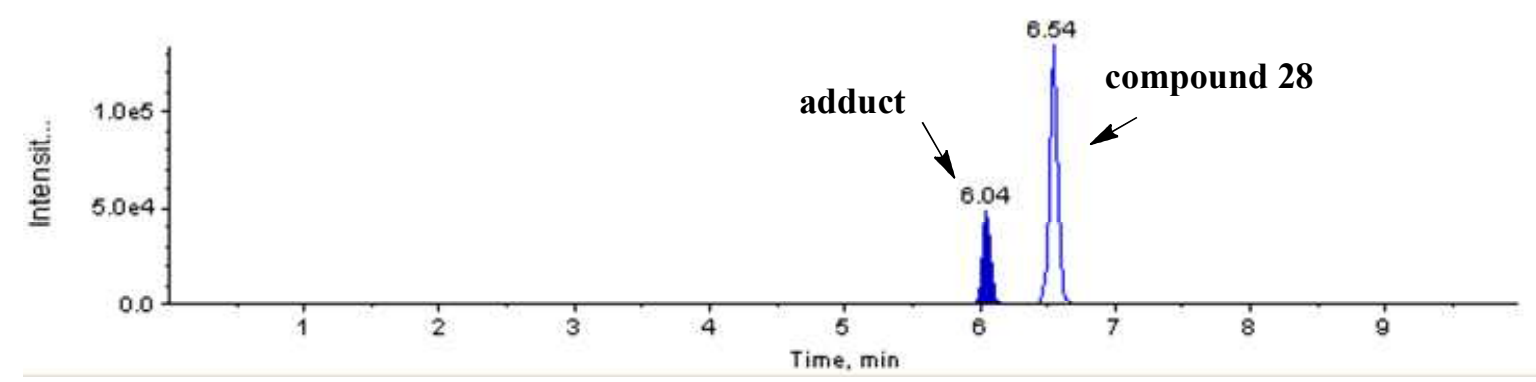

Figure 3. LC/MS/MS Chromatograms of compound 28 enzyme reaction mixture: (a) Multiple Reaction Monitoring (MRM) of transition from m/z 604.0 (adduct $\mathrm{M}+\mathrm{H}$ ion) to 392.3 (parent $\mathrm{M}+\mathrm{H}$ ion) indicating presence of phosphoribosylated adduct (b) $\mathrm{MRM}$ of transition from $\mathrm{m} / \mathrm{z}$ 392.3 (parent $\mathrm{M}+\mathrm{H}$ ion) to 125.0 (representing fragmentation of the left hand side of the parent) indicating presence of both parent (28) and phosphoribosylated adduct.

\section{LC/MS/MS method and results for compound 33}

HPLC Separation

Column - ACE $3 \mathrm{C} 18,3 \mu \mathrm{m},(50 \mathrm{~mm} \times 2.1 \mathrm{~mm})$

Mobile Phase A: $\mathrm{H}_{2} \mathrm{O}, 1 \%$ Formic Acid 
Mobile Phase B: Acetonitrile, 1\% Formic Acid

Gradient Programs

\begin{tabular}{|c|c|c|}
\hline $\begin{array}{c}\text { Time } \\
(\mathrm{min})\end{array}$ & $\begin{array}{c}\% \text { Mobile } \\
\text { Phase B }\end{array}$ & $\begin{array}{c}\text { Flow Rate } \\
(\mu \mathrm{L} / \mathrm{min})\end{array}$ \\
\hline 0.0 & 15 & 400 \\
\hline 0.5 & 15 & 400 \\
\hline 7.5 & 95 & 400 \\
\hline 8.5 & 95 & 400 \\
\hline 8.6 & 15 & 400 \\
\hline 10 & 15 & 400 \\
\hline
\end{tabular}

Injection Volume: $10 \mu \mathrm{L}$

Mass Spectrometry

API 4000 (Applied Biosystem /Sciex) 


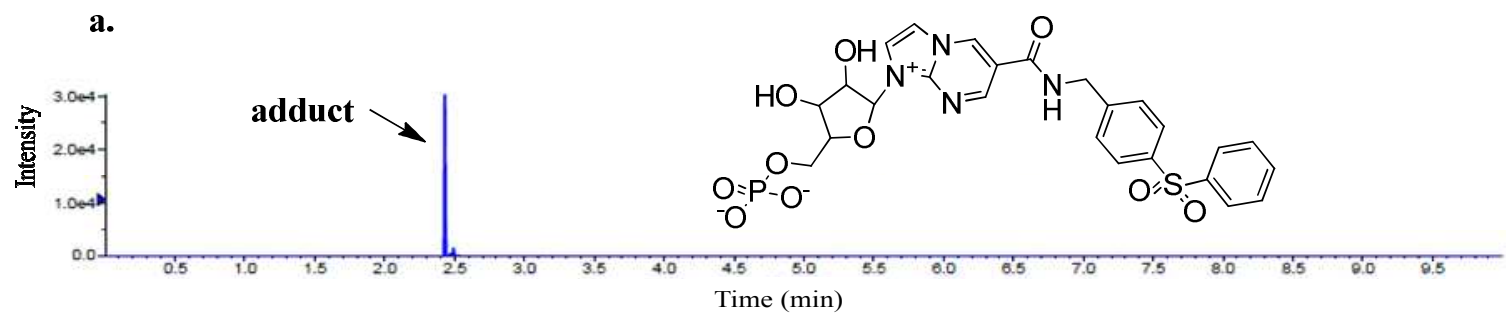

b.

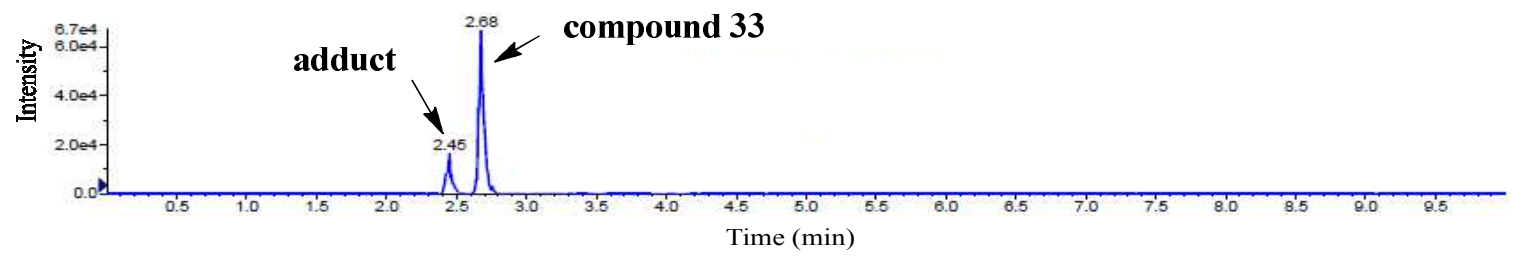

Figure 4. LC/MS/MS Chromatograms of compound 33 enzyme reaction mixture: (a) Multiple Reaction Monitoring (MRM) of transition from m/z 605 (adduct $\mathrm{M}+\mathrm{H}$ ion) to 393 (parent $\mathrm{M}+\mathrm{H}$ ion) indicating absence of phosphoribosylated adduct (b) MRM of transition from $\mathrm{m} / \mathrm{z} 393$ (parent $\mathrm{M}+\mathrm{H}$ ion) to 148 (representing fragmentation of the left hand side of the parent) indicating presence of both parent (33) and phosphoribosylated adduct. 


\section{In vitro ADME assays}

\section{Microsomal stability assay}

Test compounds $(1 \mu \mathrm{M})$ were incubated in $0.1 \mathrm{M}$ phosphate buffer $\left(\mathrm{pH} 7.4\right.$ at $\left.37{ }^{\circ} \mathrm{C}\right)$ containing human or mouse microsomes $(0.5 \mathrm{mg} / \mathrm{mL})$ and an NADPH-generating system. Stock solutions $(100 \mu \mathrm{M})$ of compounds were made in acetonitrile/water $(50 / 50, \mathrm{v} / \mathrm{v})$ along with reference compounds that showed high, medium, and low \% remaining at 30 minutes. The reaction was initiated by the addition of the NADPH-generating system. Thereafter, the 0,10 , and 30 minute time points were taken and added to appropriate volumes of cold acetonitrile containing an internal standard. The signal was measured by LCMS and the \% remaining of test compound relative to the 0 minute time point was calculated.

\section{Hepatocytes stability assay}

The metabolic stability of tested compounds $(1 \mu \mathrm{M})$ was evaluated in female pooled CD-1 mouse cryopreserved primary hepatocytes or pooled human cryopreserved primary hepatocytes $\left(0.5\right.$ million cells $\left.\mathrm{mL}^{-1}\right)($ Celsis, Baltimore, $\mathrm{MD})$. Incubations (final incubation volume $=250$ $\mu \mathrm{L})$ were performed at $37^{\circ} \mathrm{C}$ under an atmosphere of $5 \% \mathrm{CO}_{2}$ in DMEM. Aliquots $(50 \mu \mathrm{L})$ of the reaction mixture were added to $100 \mu \mathrm{L}$ ice-cold acetonitrile with internal standard at $0,1,2$ and $3 \mathrm{~h}$ and the samples were centrifuged at $3000 \mathrm{~g}$ for $10 \mathrm{~min}$. Supernatant $(80 \mu \mathrm{L})$ was diluted in water $(160 \mu \mathrm{L})$ before LC-MS/MS analysis. 
The hepatic clearance $\left(\mathrm{CL}_{\mathrm{hep}}\right.$, or predicted hepatic clearance) is calculated using the wellstirred model and is scaled from the $\mathrm{CL}_{\text {int }}$. Scaling factors are listed in the table below. The fraction unbound in the hepatocyte incubation and in blood was assumed to be 1 .

\begin{tabular}{|c|c|c|}
\hline \multirow[t]{2}{*}{ Parameters } & \multicolumn{2}{|c|}{ Species } \\
\hline & Human & Mouse \\
\hline number of hepatocytes/g liver weight ${ }^{\mathrm{a}}$ & $1.35 \times 10^{8}$ & $1.20 \times 10^{8}$ \\
\hline g liver weight $/ \mathrm{kg}$ body weight ${ }^{\mathrm{b}}$ & 25.7 & 87.5 \\
\hline liver blood flow $(\mathrm{mL} / \mathrm{min} / \mathrm{kg})^{\mathrm{b}}$ & 20.7 & 90 \\
\hline
\end{tabular}

${ }^{a}$ Houston, J. (1994), Biochem. Pharm. 47:1469-1479

\section{Solubility assay}

Stocks of $10 \mathrm{mM}$ drug solutions in DMSO were diluted into universal phosphate buffer to a maximum concentration of $100 \mu \mathrm{M}$. The $1 \%$ DMSO buffered drug solutions were incubated over a period of 24 hours and then were filtered through a 96 well Millipore Multi-Screen plate. Standards were prepared at $100 \mu \mathrm{M}$ in neat DMSO. Analyses were carried out by LCMS and compound solubility was determined by the ratio of the UV signal of the filtrate peak versus to that of the corresponding $100 \mu \mathrm{M}$ standard.

\section{Madin-Darby Canine Kidney I (MDCK) Permeability}


The Madin-Darby canine kidney (MDCK) cell line was acquired from the American Type Culture Collection (Manassas, VA). The cells were seeded at an initial concentration of $2.5 \times 10^{5}$ cells $/ \mathrm{mL}$ in 24 well plates and allowed to grow for 4 days at $37{ }^{\circ} \mathrm{C}, 95 \%$ humidity, and $5 \% \mathrm{CO}_{2}$ in culture with Eagle's Minimum Essential Medium Earle's BSS $(0.1 \%$ non essential amino acids, $1 \mathrm{mM}$ sodium pyruvate, $2 \mathrm{mM}$ L-glutamine, $1.5 \mathrm{~g} / \mathrm{L}$ sodium bicarbonate) supplemented with $10 \%$ fetal bovine serum. The MDCKI monolayers were equilibrated for 30 minutes in transport buffer (HBSS with $10 \mathrm{mM}$ HEPES, pH 7.4 ) at $37^{\circ} \mathrm{C}$ with $5 \% \mathrm{CO}_{2}$ and $95 \%$ humidity prior to the experiment. The permeability of test compounds was examined at $10 \mu \mathrm{M}$ in the apical to basolateral (A-to-B) direction. The dose solutions also contained the monolayer integrity marker LY $(100 \mu \mathrm{M})$ and a final DMSO percentage of $1 \%$. The test compounds were analyzed by LC-MS/MS. The apparent permeability $\left(\mathrm{P}_{\mathrm{app}, \mathrm{A}-\mathrm{B}}\right)$ was calculated using the following equation:

$$
\mathrm{P}_{\mathrm{app}, \mathrm{A}-\mathrm{B}}=\frac{\mathrm{dQ}}{\mathrm{dt}} \cdot \frac{1}{\mathrm{C}_{0}} \cdot \frac{1}{\mathrm{~A}}
$$

Where $\mathrm{dQ} / \mathrm{dt}$ is the rate of compound appearance in the receiver compartment ( $\mathrm{Q}$ is the quantity of compound), $\mathrm{C}_{0}$ is the concentration in the donor compartment and $\mathrm{A}$ is the surface area of the insert.

\section{Reversible Plasma Protein Binding}


The extent of protein binding $(\mathrm{n}=2)$ was determined in vitro in pooled mouse plasma (Bioreclamation, Inc., Hicksville, NY) by equilibrium dialysis using a Rapid Equilibrium Dialysis (RED) device (Pierce Biotechnology / Thermo Fisher Scientific; Rockford, IL) in 96well format with a molecular weight cut-off of 8000 Daltons. Test compounds were dissolved in dimethyl sulfoxide (DMSO), and added to plasma, for a final concentration of $5 \mu \mathrm{M}$ in the plasma. The final DMSO percentage was $1 \% .300 \mu \mathrm{L}$ plasma containing compound were dialyzed against $500 \mu \mathrm{L}$ PBS on a shaking platform in a humidified incubator for 4 hours at 37 ${ }^{\circ} \mathrm{C}$. Post-equilibrium buffer and plasma samples were transferred to a 96-well plate and opposing matrix was added. Plasma proteins were precipitated using $100 \%$ acetonitrile containing internal standard (100 nM propranolol). Concentration of compounds in plasma and PBS were measured by LC-MS/MS and the percent bound fraction $\left(\mathrm{f}_{\mathrm{b}}\right)$ was calculated using the equation:

$f_{b}=\left(1-\frac{\text { PA in Buffer/IS PA }}{\text { PA in Plasma/IS PA }}\right) \cdot 100 \%$

where PA represents analyte peak area and IS PA represents internal standard peak area. 


\section{In vitro Methods for the Determination of Nampt Inhibition and Cell Proliferation}

\section{Biochemical Assay}

\section{Part 1: The Nampt enzymatic reaction}

The Nampt enzymatic reactions were carried out in Buffer A (50 mM Hepes pH 7.5, $50 \mathrm{mM}$ $\mathrm{NaCl}, 5 \mathrm{mM} \mathrm{MgCl}$, and $1 \mathrm{mM} \mathrm{THP)}$ in 96-well plates. The compound titrations were performed in a separate dilution plate in DMSO to make a 100x stock. Nampt protein (XTAL Biostructures, MA) in $89 \mu \mathrm{L}$ Buffer A was added to $1 \mu \mathrm{L}$ compound, incubated for 15 minutes at room temperature, and then $10 \mathrm{x}$ substrate and co-factors were added to the test well to make a final concentration of $30 \mathrm{nM}$ Nampt, $1 \mu \mathrm{M}$ NAM, $100 \mu \mathrm{M}$ PRPP, and $2.5 \mathrm{mM}$ ATP. The reaction was allowed to proceed for 30 minutes at room temperature, and then was quenched with formic acid and L-Cystathionine to make a final concentration of $1 \%$ formic acid and 10 $\mu \mathrm{M}$ L-Cystathionine.

\section{Part 2: Quantification of NMN}

A mass spectrometry-based assay was used to measure the Nampt reaction product (NMN) and the internal control (L-Cystathionine). NMN and L-Cystathionine were detected using the services of Agilent with the RapidFire system. In short, the NMN and L-Cystathionine were bound to a graphitic carbon cartridge in $0.1 \%$ formic acid, eluted in $30 \%$ acetonitrile buffer, and injected into a Sciex 4000 mass spectrometer. The components of the sample were ionized with electrospray ionization and the positive ions were detected. The Q1 (parent ion) and Q3 (fragment ion) masses of NMN were 334.2 and 123.2, respectively. The Q1 and Q3 for LCystathionine were 223.1 and 134.1, respectively. 


\section{In vitro Cell Proliferation Assays}

\section{A2780 Cell-Based Assays}

A2780 cells were seeded in 96-well plates at 1 x 103 cells/well in $180 \mu \mathrm{L}$ of culture medium (10\% FBS, 1\% Pen/Strep Amphotecricin B, RPMI-5 1640) with and without the addition of either nicotinamide mononucleotide $(\mathrm{NMN})$. After overnight incubation at $37^{\circ} \mathrm{C}$ and $5 \% \mathrm{CO}_{2}$, the compounds were added to cells with a final DMSO concentration of $0.1 \%$. The plates were then incubated for 72 hours at $37^{\circ} \mathrm{C}$ in a $5 \% \mathrm{CO}_{2}$ incubator. The number of viable cells was then assessed using sulforhodamine B (SRB) assay. Cells were fixed at $4{ }^{\circ} \mathrm{C}$ for 1 hour with the addition of TCA to make a final concentration of $6 \%$ TCA. The plates were washed with $\mathrm{H}_{2} \mathrm{O}$ and dried, whereupon $100 \mu \mathrm{L}$ of a $4 \%$ SRB in $1 \%$ acetic acid solution was added to each well and incubated at room temperature. The plates were then washed with $1 \%$ acetic acid, dried, and treated with $100 \mu \mathrm{L}$ of $10 \mathrm{mM}$ Tris-Base solution. The plates were then read in a microplate reader at an absorbance of $570 \mathrm{~nm}$.

\section{Other Cell-Based Assays}

$1 \times 10^{3}$ cells were plated in Black-clear bottom 384 well plates (BD Falcon 353962) for 24 hours. Cells then were treated with a dose titration of compounds for 96 hours. Viability was measured with CyQuant-Direct (Invitrogen, C35011) according to manufacturer's instruction: 3x concentration of CyQuant reagent was added to cells at $1: 2$ ratio. Plates were incubated at $37^{\circ} \mathrm{C}$ for 1 hour and read on Envision plate reader. The experiment was independently run three times with triplicate samples for each time. $\mathrm{IC}_{50}$ curves were generated with GraphPad Prism. $\mathrm{IC}_{50}$ obtained from each run were then averaged in Excel and STDEV were calculated and shown. 


\section{In vivo pharmacodynamics and efficacy studies}

\section{PK study method}

Female NCR nude mice were obtained from Taconic (Cambridge City, IN, US). 12 animals were given a single intravenous dose of $5 \mathrm{mg} / \mathrm{kg}$ of compound $\mathbf{5 8}$ via the tail vein, and 12 animals were given a single oral dose of $10 \mathrm{mg} / \mathrm{kg}$ of compound $\mathbf{5 8}$. The dose solutions for IV and PO were in 35\% polyethylene glycol (PEG 400)/10\% ethanol/15\% PG/40\% $\mathrm{H}_{2} \mathrm{O}(\mathrm{v} / \mathrm{v} / \mathrm{v})$ and $60 \%$ polyethylene glycol (PEG 400)/10\% ethanol/30\% $\mathrm{H}_{2} \mathrm{O}(\mathrm{v} / \mathrm{v} / \mathrm{v})$, respectively. Mice weighed approximately $25-30 \mathrm{~g}$ at the start of the study, and they were not fasted for dosing. After intravenous and oral administration of compound $\mathbf{5 8}(\mathrm{n}=3$ per time point), each animal was bled twice via retro orbital $(150 \mu \mathrm{L}$ of blood was collected $)$ and cardiac puncture $(200 \mu \mathrm{L}$ of blood was collected) under isoflurane anesthesia. PK time points were 0.033 (IV administration only), 0.083 (PO administration only), 0.17 (IV administration only), 0.25 (oral administration only), $0.5,1,3,6,8$ and 24 hours post-dose. Blood samples were collected into 1.5\% EDTA-containing syringes, transferred to microcentrifuge tubes and spun to harvest plasma. Plasma was collected, transferred to cluster tubes, and stored at approximately $-80{ }^{\circ} \mathrm{C}$ until thawed for LC-MS/MS analysis (Column: Kinetex 50 x 2.1 mm C18 2.6 u 100A; Mobile phase: (water with 0.1\% formic acid and $\mathrm{MeCN}$ with $0.1 \%$ formic acid); ionization: electrospray positive ion mode; data acquisition: Analyst version 1.5.2. PK data analysis was performed on mean plasma concentration-time data and PK parameters were determined by non-compartmental methods using WinNonlin ${ }^{\circledR}$ Enterprise, version 5.2.1 (Pharsight Corporation; Mountain View, CA). 


\section{In vivo Xenograft Studies:}

The efficacy study was carried out as per the guidelines established by the internal Institutional Animal Care and Use Committee. Prior to the implantation, the U251 cells were harvested, washed twice with PBS and resuspended in serum free medium containing Matrigel (BD Biosciences) in the ratio $1: 1$. To determine the efficacy of the test compounds, female athymic nude mice were inoculated with $5 \times 10^{6} \mathrm{U} 251$ cells subcutaneously in right flank. The animals were then monitored for their tumor growth. Tumors were allowed to grow to a predetermined size $\left(100-200 \mathrm{~mm}^{3}\right)$ and were then evenly randomized into control and treatment groups $(\mathrm{n}=8)$. Animals in the treatment group were administered the test substance (compound 58; $25 \mathrm{mg} / \mathrm{kg}$ BID) according to their individual body weight for the described period of time and observed for treatment related toxicity. Tumor volume was measured thrice per week with a digital vernier caliper according to the formula $\mathrm{Lx} \mathrm{W}^{2} / 2$ where $\mathrm{L}$ and $\mathrm{W}$ are the length (mm) and width (mm) of the tumor, respectively. Tumor response endpoints such as \% Tumor Growth Inhibition (\% TGI) were also calculated. 